\title{
The Regulatory Roles of MicroRNAs in Bone Remodeling and Perspectives as Biomarkers in Osteoporosis
}

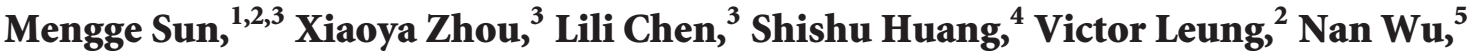 \\ Haobo Pan, ${ }^{3}$ Wanxin Zhen, ${ }^{1}$ William Lu, ${ }^{2,3}$ and Songlin Peng ${ }^{1,2,3}$ \\ ${ }^{1}$ Department of Spine Surgery, Shenzhen People’s Hospital, Jinan University School of Medicine, Shenzhen 518020, China \\ ${ }^{2}$ Department of Orthopaedics and Traumatology, The University of Hong Kong, 21 Sassoon Road, Pokfulam, Hong Kong \\ ${ }^{3}$ Center for Human Tissues and Organs Degeneration, Shenzhen Institute of Advanced Technology, Chinese Academy of Sciences, \\ Shenzhen 518055, China \\ ${ }^{4}$ Department of Orthopaedic Surgery, West China Hospital, Sichuan University, Chengdu 610041, China \\ ${ }^{5}$ Department of Orthopedic Surgery, Peking Union Medical College Hospital, Beijing 100730, China
}

Correspondence should be addressed to William Lu; wwlu@hku.hk and Songlin Peng; songlin824@gmail.com

Received 5 December 2015; Revised 26 February 2016; Accepted 29 February 2016

Academic Editor: Jozef Zustin

Copyright (C) 2016 Mengge Sun et al. This is an open access article distributed under the Creative Commons Attribution License, which permits unrestricted use, distribution, and reproduction in any medium, provided the original work is properly cited.

MicroRNAs are involved in many cellular and molecular activities and played important roles in many biological and pathological processes, such as tissue formation, cancer development, diabetes, neurodegenerative diseases, and cardiovascular diseases. Recently, it has been reported that microRNAs can modulate the differentiation and activities of osteoblasts and osteoclasts, the key cells that are involved in bone remodeling process. Meanwhile, the results from our and other research groups showed that the expression profiles of microRNAs in the serum and bone tissues are significantly different in postmenopausal women with or without fractures compared to the control. Therefore, it can be postulated that microRNAs might play important roles in bone remodeling and that they are very likely to be involved in the pathological process of postmenopausal osteoporosis. In this review, we will present the updated research on the regulatory roles of microRNAs in osteoblasts and osteoclasts and the expression profiles of microRNAs in osteoporosis and osteoporotic fracture patients. The perspective of serum microRNAs as novel biomarkers in bone loss disorders such as osteoporosis has also been discussed.

\section{Introduction}

MicroRNA (miRNA) is a small noncoding RNA molecule (containing about 22 nucleotides) found in plants, animals, and some viruses, which also has functions in RNA silencing and posttranscriptional regulation of gene expression [1]. miRNAs interact with targets that have similar sequences, which inhibits translation of different genes, although miRNAs are not completely complementary to the mRNA sequence. miRNAs have been reported to impact on the expression of $1 \% \sim 4 \%$ human genes by regulating about $30 \%$ human mRNAs [2]. Therefore, miRNAs play an important role in many biological processes, such as tissue formation [3-7], cancer development [8], diabetes [9], neurodegenerative diseases [10], systemic autoimmunity diseases [11], and cardiovascular diseases [12]. Interestingly, miRNAs have also been identified to be involved in the process of bone remodeling and many bone metabolic diseases, such as osteoporosis $[13,14]$.

The maintenance of bone mass mainly depends on the balance between osteoblast-mediated bone formation and osteoclast-mediated bone resorption [15]. Several miRNAs have been reported to regulate bone metabolism by modulating the differentiation and activity of osteoblasts and osteoclasts, such as miR-223 [16] and miR-103a [17]. Therefore, miRNAs are regarded as one of the important modulators in the bone remodeling. In this review, we will discuss the mechanisms of microRNAs involved in the bone formation and resorption, in particular the relationship between miRNAs and osteoblasts/osteoclasts. Furthermore, we present the recent reports on the expression profiles of 


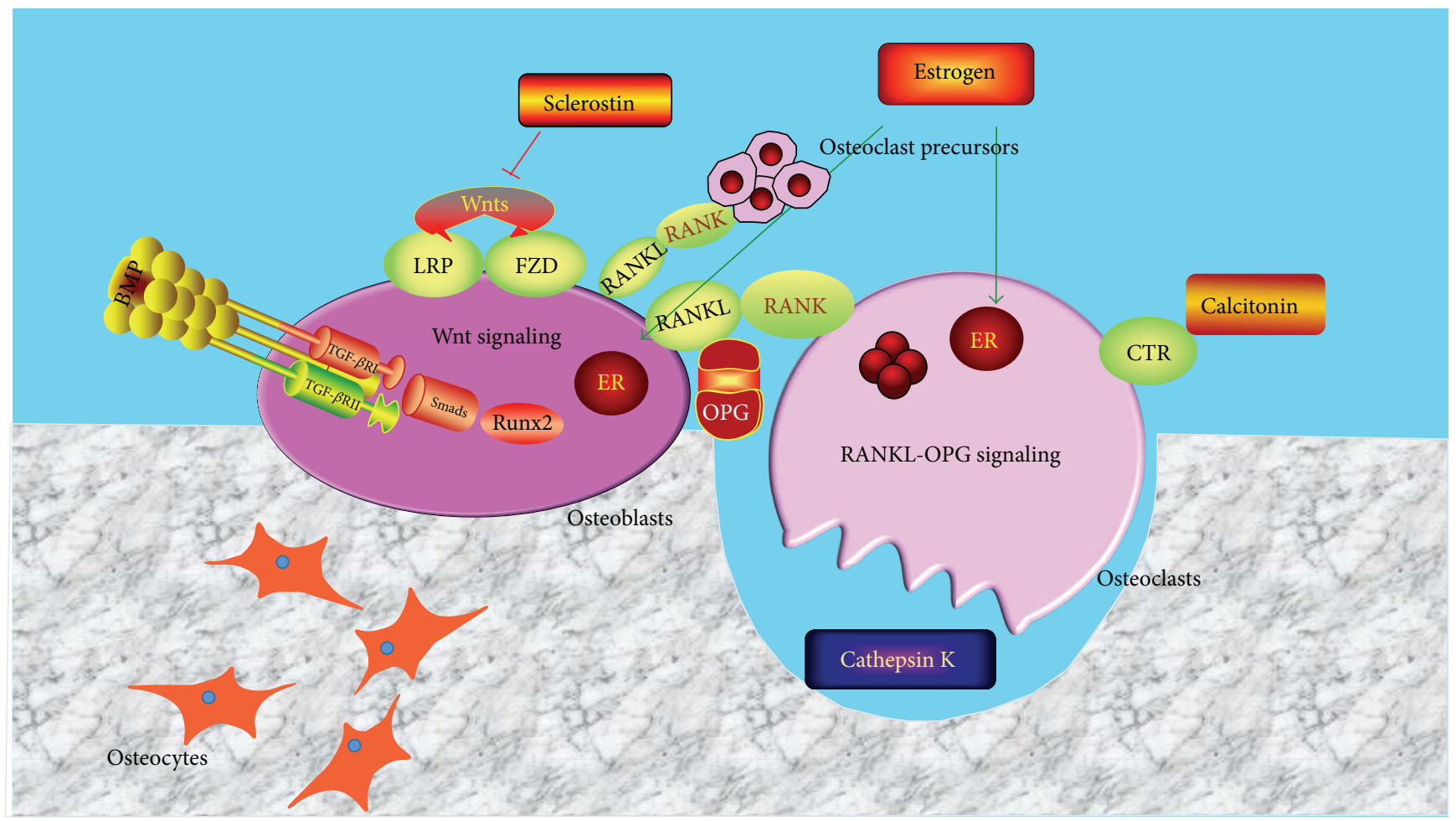

FIGURE 1: Bone cell interactions and key signaling pathways during bone remodeling. Osteoblasts induce RANKL and regulate the differentiation of osteoclast precursors. Meanwhile, the binding of RANKL and RANK stimulates the activity of osteoclasts. OPG produced by osteoblasts competitively binds to RANKL, resulting in the inhibition of osteoclasts differentiation. FZD and LRP form a coreceptor for Wnt ligand. The combination between Wnt ligand and its receptor results in the enhancement of osteoblast differentiation. Heterodimers of Ser/The form the receptor of BMPs. BMPs are regulated by Smads and Runx2.

miRNAs in osteoporosis and osteoporotic fracture patients. We hope this review will shed new light on the understanding of the characteristics of miRNA in bone remodeling and bone loss disorders.

\section{Key Signal Pathways Involved in Bone Remodeling}

Osteoblasts are differentiated from mesenchymal stromal cells (MSCs) through several key signaling pathways such as Wnt and BMP. Osteoclasts are originated from mononuclear precursors through RANKL-OPG signaling pathway. Although various cell types are involved in the process of bone remodeling, RANKL-OPG, Wnt, and BMP pathways have been identified as the classic pathways in the process of bone remodeling [18] (Figure 1).

2.1. RANKL-OPG Pathways. Osteoblasts and their progenitors are one of the key cell types in bone formation. Osteoblasts secrete numerous factors such as macrophage colony stimulating factor (M-CSF) and receptor activator of $\mathrm{NF}-\kappa \mathrm{B}$ ligand (RANKL), which regulate the differentiation of osteoclast progenitors. Osteoclast progenitors finally generate mature osteoclast with markers, such as tartrate resistant acid phosphatase (TRAP) [19], calcitonin receptors [20], cathepsin K [21], and matrix metalloproteinase 9 (MMP9)
[22], and alpha v beta 3 integrin chains $\left(\alpha_{\mathrm{v}} \beta_{3}\right)$ [23]. RANK is an important regulator of osteoclast precursors, along with CD14, CD11b, and cFms [24]. The binding of RANKL and RANK would affect many signaling pathways in the regulation of osteoclastogenesis, such as NF- $\kappa \mathrm{B}$ [25]. Osteoprotegerin (OPG) is a decoy protein secreted by osteoblasts and it could bind to RANKL, leading to the blocking of binding of RANKL and RANK and the inhibition of osteoclastogenesis. The RANKL-OPG pathway has been identified as a key regulator in the cross-talk between osteoblast-mediated bone formation and osteoclast-mediated bone resorption.

2.2. Wnt Pathways. The Wnt pathways are involved in bone homeostasis and bone remodeling process [26]. Wnts are regarded as anabolic factors that enhance the proliferation and differentiation of osteoblast progenitors [27-29]. Specific Frizzled (FZD) proteins and the low-density lipoprotein receptor related protein 5/6 (LRP-5/6) formed a receptor complex for Wnt ligand. With the binding of Wnt ligand, LRP-5, or LRP-6, $\beta$-catenin is released and become stabilized. Subsequently, $\beta$-catenin is translocated to the nucleus and regulates its target genes including Runx2 with the help of transcription factor 4 (TCF-4) or lymphoid enhancerbinding factor 1 (LEF-1) [30]. Additionally, Wnt signaling enhances osteoblast differentiation of bone marrow mesenchymal stem cells (MSCs) by increasing the level of Runx2 
and osterix. On the other hand, Wnt signaling could suppress the differentiation of adipose-derived stem cells to adipocytes by inhibiting the adipogenic factors CCAAT/enhancerbinding protein $\alpha(\mathrm{C} / \mathrm{EBP} \alpha)$ and peroxisome proliferatoractivated receptor $\gamma(\operatorname{PPAR}-\gamma)$. Furthermore, Wnt signaling has impact on the suppression of osteoclast activity by secreted Frizzled-related protein 1 (Sfrp1), a binding site of Frizzled proteins. Sfrpl competitively binds to RANKL, which reduces bone resorption [31,32]. $\beta$-Catenin inhibits the level of OPG. Therefore, lower level of $\beta$-catenin in osteoblast progenitors resulted in bone loss [33].

There are also other regulators involved in the regulation of Wnt signaling pathways. For example, insulin-like growth factor 1 (IGF-1) interrupts the proteolytic degrading activity of $\beta$-catenin by affecting its stability and transcriptional activity [34]. Notch has been identified in the association to Wnt and acts by the degrading process of $\beta$-catenin [35]. Sclerostin, an antagonist of Wnt signaling, is found to be highly expressed in osteocytes by binding to LRP5/6. This process competitively affects the binding of Wnt and LRP5/6 [36]. Therefore, Wnt/ $\beta$-catenin is a key signaling pathway for osteoblasts differentiation and activities.

2.3. BMP Pathways. Bone morphogenetic proteins (BMPs) are cytokines and belong to the members of transforming growth factor- $\beta$ (TGF- $\beta$ ) superfamily. Heterodimers of Ser/The form the receptor of BMPs. BMPs are regulated by RSmads (Samd1, Smad5, and Smad8) and Co-Smad (Smad4). The interaction between BMPs and their receptors stimulates the phosphorylation of Smads. The phosphorylated R-Smads form a complex with their common partner Smad4 and enter the nucleus to modulate gene expression and enhance osteogenesis [37].

Runt-related transcription factor 2 (Runx2), belonging to the Runx transcriptional factors family, connects many signal pathways in bone remodeling process by regulating osteoblast differentiation [38]. Runx2 regulates the gene related to bone formation such as osteopontin (OPN), bone sialoprotein (BSP) [39], and osteocalcin (OCN) [40]. It also enhances the level of PI3K/Akt [41]. Osterix, the downstream mediator for Runx 2 actions during osteoblast differentiation, regulates the differentiation and function of osteoblasts and osteocytes, which is crucial for bone formation and bone resorption [42]. Runx2 is crucial in the activation of Smads by BMPs as well. Runx2 knockout mice exhibit defect in osteogenic activity [43]. Histone deacetylases (HDACs) are conserved enzymes that remove acetyl groups from lysine side chains in histones and other proteins and modulate gene expression in transcriptional corepressor complexes [44]. Among all HDAC family members, HDACl and HDAC3 are the most abundant in bone tissue [45]. HDAC5 bound to Smad3 in response to TGF- $\beta$ and inhibited Runx2 activity [46]. HDAC9 was found to decrease in the process of osteoclastogenesis by inhibiting peroxisome proliferator-activated receptor gamma $(\operatorname{PPAR} \gamma)$ and receptor activator of nuclear factor kappa$B$ ligand (RANKL). In HDAC9 knockout mouse, the level of bone resorption was upregulated [47]. The fibroblast growth factors (FGF) pathway initiates the mesenchyme and proliferation of progenitor cells via transducing their signal through the FGF receptors (FGFRs). FGFRs contribute to normal skeletal development. The activation of FGFR2 signaling especially triggers increased Runx2 expression and enhanced osteoblast differentiation [48]. HOXA10 contributes to osteogenic lineage determination through activation of Runx 2 and directly regulates osteoblastic phenotypic genes. In response to BMP2, HOXA10 is rapidly induced and functions to activate the Runx2, the transcription factor essential for bone formation. HOXA10 also activates other osteogenic genes, such as the alkaline phosphatase and osteocalcin [49]. FAK is not a necessary modulator for osteoblasts differentiation. However, once osteoblasts secrete their collagen type I, FAK-dependent integrin signaling appears to be critical for the structural protein to form an intact osteoid matrix [50].

\section{Regulatory Roles of MicroRNAs in Bone Remodeling}

miRNAs are endogenous noncoding RNA molecules and silence the transcription of mRNA by specifically binding to its target sequence. miRNAs play important roles during tissue development. In 2004, Chen et al. reported that miR-181 was strongly expressed in the B-lymphoid cells of mouse bone marrow [51]. Two years later, miR-140 was reported to be specifically expressed in cartilage tissue [52]. Cartilage is the major component of the skeletal system in early embryo stage. These studies indicate that miRNAs could be involved in the regulation of skeletal system. In particular, miRNAs have been reported to be involved in the modulation of osteoblasts and osteoclasts, two key regulators in the bone remodeling process.

3.1. Regulatory Roles of MicroRNAs in Osteoblasts. As a dynamic tissue, the maintenance of bone mainly depends on the balance between osteoblast-mediated bone formation and osteoclast-mediated bone resorption [15]. Osteoblasts are generated by bone marrow mesenchymal stem cells (BMSCs), synthesizing thickly, cross-linked collagen to constitute the major cellular ingredient of bone. From the morphological point of view, osteoblasts are cubical shaped cells with plenty of plasma. The cytoplasm of osteoblasts is in a strong basophilia state. Osteoblasts are found positive for periodic acid-Schiff staining and intensely positive for the alkaline phosphatase staining. Osteoblasts secrete osteocalcin and osteopontin, together with mineral to form bone matrix [53]. Osteoblasts continuously refill the bone cavity created by osteoclasts. The balance between osteoblast-mediated bone formation and osteoclast-mediated bone resorption is crucial to the bone remodeling and the homeostasis of bone metabolism.

Several specific miRNAs have been reported to be involved in the process of BMSCs differentiation into osteoblasts. For instance, miR-20a is expressed in many cell types and plays important roles in tumor proliferation and metastasis [54-57]. MiR-20a has also been identified to promote differentiation of BMSCs into osteoblasts. It directly binds to the $3^{\prime}$ untranslated region ( $3^{\prime}$ UTR) of BMP-2 [58] and activates BMP/Runx 2 signaling through silencing peroxisome proliferator-activated receptors $\gamma(\operatorname{PPAR} \gamma)$, Bambi 
and Crim1 [59]. MiR-20a is also found to be overexpressed in osteoblasts derived from dexamethasone induction by downregulating RANKL expression, subsequently suppressing osteoclastogenesis and bone resorption [60].

MiR-29a is involved in regulating many cellular processes, such as the enhancement of T-cells stimulation [61, 62] and human immunodeficiency virus (HIV) replication $[63,64]$. In skeleton system, the delivery of miR-29a inhibits the process of bone resorption in rats with glucocorticoidinduced bone loss [65]. Further in vitro study indicates that miR-29a mitigates bone loss by suppressing histone deacetylase 4 (HDAC4). This increased level of $\beta$-catenin acetylation and osteogenesis [66]. Additionally, the inhibition of HDAC4 expression could enhance Runx2 acetylation, which induce many growth factors and increase osteogenesis [67]. Furthermore, histomorphometric analyses indicate that miR-29a ameliorate the deterioration of trabecular bone volume caused by glucocorticoid in mice model. The bone mass of miR-29a transgenic mice is higher compared to that of wild-type mice [68].

MiR-15b regulates cell cycle progression and has been found to have close relationship with many kinds of cancer [69-71]. In bone remodeling process, miR-15b has been reported to play a positive role in the regulation of osteogenesis. In human BMSCs, miR-15b promotes the osteoblasts differentiation and shows a high amount of ALP and type I collagen. This process targets Smurf1 which protects Runx2 from degradation [72]. The expression level of miR-15b is also regarded as one of the criteria for the osteogenic evaluation [73].

MiR-210 is an important regulator in the setting of hypoxia [74-76]. It upregulates the expression level of vascular endothelial growth factor (VEGF) and enhances the differentiation rate of BMSCs into osteoblasts in vitro [77]. Another work completed by Mizuno et al. shows that miR-210 enhances the activity of activin-like kinase and the expression level of osteocalcin in ST2 cells by targeting activin A receptor type 1B (AcvR1b) gene [78].

MiR-216a shows a remarkable inhibitory effect on pancreatic tumor [79-81]. In human adipose-derived MSCs, miR216a could significantly enhance their differentiation to osteoblasts by targeting c-Cbl. This induces phosphatidylinositol 3 kinase (PI3K)/AKT pathway in bone metabolism [82].

MiR-2861 has been reported to regulate the osteogenic differentiation of BMSCs. In mice, miR-2861 enhances osteoblasts differentiation by targeting histone deacetylase 5 (HDAC5) [83]. As HDAC5 deacetylates Runx2, the suppression of HDAC5 could elevate osteogenesis. MiR-3960 and miR-2861 are gathered at the same genetic locus. MiR-3960 regulates osteoblast differentiation through a modulation feedback loop with miR-2861 in primary mouse osteoblasts [84]. The target of miR-3960 is Homeobox A2 (Hoxa2) that is an inhibitor of Runx2. Additionally, the Runx2/miR-3960/ miR-2861 regulation loop enhances osteogenic differentiation of vascular smooth muscle cells of mice with increased level of alkaline phosphatase (ALP) and osteocalcin (OC) [85].

It should be noted that miRNAs not only play a positive regulatory role in osteoblasts differentiation and activities, but also play a negative regulatory role. For instance, miR-204 inhibits osteoblast-related gene expression such as Runx2, osteopontin, and osteocalcin and decreased ALP activity of osteoblasts and bone matrix formation [86, 87]. Liao et al. demonstrated that miR-705 and miR-3077-5p suppressed osteoblast differentiation in vitro by inhibiting Homeobox A10 (HOXA10) and Runx2 mRNA, respectively [88]. Liu et al. demonstrated that miR-338-3P suppressed the expression level of osterix, a transcription factor for osteoblast differentiation in BMSCs by targeting Runx2 and Fgfr2 [89]. Moreover, resveratrol could prevent the bone loss in ovariectomized rats by inhibiting miR-388-3P [90]. MiR-125b shows a negative effect on osteogenesis by targeting osterix. The proliferation rate of hBMSCs is significantly decreased when transfected with miR-125b by MTT analysis. Meanwhile, qPCR results show that the levels of ALP, collagen $\alpha 1$, and osteocalcin were reduced as well, indicating that osteogenic differentiation was suppressed [91]. Interestingly, miR-637 shows an inhibitory effect on osteoblasts by targeting osterix as well [92]. MiR188 has been reported to modulate the osteogenesis process by targeting histone deacetylase 9 (HDAC9) and RPTORindependent companion of MTOR complex 2 (RICTOR). HDAC9 is a key factor that suppresses adipogenesis of BMSCs through PPAR $\gamma$. RICTOR, as a crucial member of mTORC2, also inhibits PPAR $\gamma$ activity. The level of miR188 in older mice is significantly higher than that in young mice. MiR-188 knockout mice exhibit reduced cortical bone loss [93]. MiR-141-3p suppresses osteoblast differentiation by targeting cell division cycle 25A in hBMSCs with decreased ALP and collagen [94]. MiR-138 has been reported to inhibit osteoblast differentiation by targeting the focal adhesion kinase (FAK). FAK activated ERK1/2 by the interaction with ECM proteins; the activated ERK1/2 further induces the phosphorylation of Runx $2 / \mathrm{Cbfa}-1$, affecting osteogenic gene expression [95]. Our group also found that miR-138$5 \mathrm{p}$ impaired skeletal cell proliferation and cell differentiation. We also found that miR-675-5p impaired skeletal cell proliferation, cell differentiation, and cell adhesion. MiR-675-5p induced MC3T3-E1 cell apoptosis more specifically than miR138-5p [96].

3.2. Regulatory Roles of MiRNAs in Osteoclasts. MiR-503 has been reported to suppress osteoclastogenesis in CD14+ PBMCs by downregulating the expression of receptor activator of nuclear factor- $\kappa \mathrm{B}$ (RANK). The level of miR503 is significantly lower in the serum of patients with postmenopausal osteoporosis than that of healthy control group. Additionally, micro-CT results of OVX mice femoral diaphysis show that the trabecular number is decreased with the addition of antago-miR-503 [97]. On the other hand, the positive effect of microRNAs on osteoclastogenesis has also been reported. For instance, miR-148a is upregulated during the process of osteoclasts differentiation. Microarray analysis showed a lower BV/TV of the trabecular bone measured in agomiR-148a-treated mice by $\mu \mathrm{CT}$ indicating the positive effect of miR-148 on bone resorption in vivo [98]. Moreover, TRAP staining also reveals that miR-9 and miR-181a enhance osteoclasts survival rate [99]. Further study showed that the inhibition of miR-181a by estrogen could accelerate BMSCsinduced osteoclasts apoptosis [100]. The reported miRNAs 
TABLE 1: The current research related to miRNAs involved in osteoblast and osteoclast differentiation.

\begin{tabular}{|c|c|c|c|}
\hline MicroRNA & Effect & Target & Reference \\
\hline \multicolumn{4}{|c|}{ MiRNAs related to osteoblasts differentiation } \\
\hline MiR-210 & Upregulate & VEGF & {$[77]$} \\
\hline MiR-216a & Upregulate & Cb1-mediated PI3K/Akt & {$[82]$} \\
\hline MiR-29a & Upregulate & Runx2 & {$[68]$} \\
\hline MiR-20a & Upregulate & BMP/Runx2 & {$[59]$} \\
\hline MiR-204 & Downregulate & Runx2 & {$[86]$} \\
\hline MiR-705 & Downregulate & HOXA10 & {$[88]$} \\
\hline MiR-3077-5p & Downregulate & Runx2 & {$[88]$} \\
\hline MiR-103a & Downregulate & Runx2 & {$[17]$} \\
\hline MiR-34c & Downregulate & BMP2 & [101] \\
\hline MiR-17-5p & Downregulate & BMP2 & {$[102]$} \\
\hline MiR-106a & Downregulate & BMP2 & {$[102]$} \\
\hline MiR-125b & Downregulate & Osterix & {$[91]$} \\
\hline MiR-637 & Downregulate & Osterix & {$[92]$} \\
\hline MiR-188 & Downregulate & $\begin{array}{c}\text { Histone deacetylase } 9 \text { (HDAC9) and } \\
\text { RPTOR-independent companion of MTOR complex } 2 \\
\text { (RICTOR) }\end{array}$ & [93] \\
\hline MiR-141-3p & Downregulate & Wnt signaling pathway & {$[94]$} \\
\hline MiR-138 & Downregulate & Focal adhesion kinase signaling pathway & {$[95]$} \\
\hline MiR-338-3P & Downregulate & Runx2 and Fgfr2 & {$[89,90]$} \\
\hline MiR-2861 & Upregulate & HDAC5 & {$[83]$} \\
\hline MiR-378 & Upregulate & Caspase-3 & {$[103]$} \\
\hline MiR-26a & Upregulate & SMAD1 & {$[104]$} \\
\hline \multicolumn{4}{|c|}{ MiRNAs related to osteoclasts differentiation } \\
\hline MiR-503 & Downregulate & RANKL & {$[97]$} \\
\hline MiR-148a & Upregulate & RANKL & {$[98]$} \\
\hline MiR-34a & Downregulate & TGF $\beta-2$ & {$[105]$} \\
\hline MiR-214 & Upregulate & PI3K/Akt & {$[106]$} \\
\hline MiR-17 & Downregulate & RANKL & {$[60]$} \\
\hline MiR-20a & Downregulate & RANKL & {$[60]$} \\
\hline MiR-26a & Downregulate & CTGF & [107] \\
\hline
\end{tabular}

involved in bone remodeling and their target genes are summarized in Table 1.

\subsection{Dual Role of MicroRNAs in Bone Remodeling Process.} MiR-34 family has been reported as cancer inhibitors by reflecting p53 pathway [108]. Interestingly, study also shows a higher level of osteogenic differentiation in mouse BMSCs with p53 deficiency [109], indicating the involvement of miR34 family in bone remodeling process. MiR-34a inhibits the differentiation of osteoclasts by targeting transforming growth factor- $\beta$-induced factor 2 (TGF $\beta-2)$. The miR-34a transgenic mice exhibit a higher bone mass [105]. On the other hand, miR-34c has been reported to inhibit the activity and differentiation of osteoblasts by targeting Notch1. In miR$34 \mathrm{c}$ transgenic mice, the value of bone volume/total volume, trabecular thickness, and trabecular number are significantly lower than that in wild-type mice, indicating that miR-34c suppressed osteoblasts differentiation [101].
MiR-26a has been demonstrated to positively regulate the differentiation of adipose tissue-derived stem cells (ADSCs) into osteoblasts by targeting SMAD1 transcription factor. SMAD1 interacts with the Homeobox C8 (Hoxc8) and leads to the activation of osteopontin gene transcription [104]. It is also confirmed by Wang et al's work that the scaffold containing miR-26a-modified ADSCs could enhance the potential of bone regeneration [110]. Interestingly, the modulation of miR-26a in BMSCs is different from that in ADSCs. MiR$26 \mathrm{a}$ in BMSCs targets GSK $3 \beta$ and Smadl and regulates Wnt and BMP signaling pathway. The increased Wnt3a and BMP2 improve mineralized nodule formation in BMSCs [111]. On the other hand, miR-26a has been reported to inhibit the osteoclastogenesis by targeting connective tissue growth factor (CTGF). TRAP staining results show that osteoclast formation was significantly suppressed by miR-26a [107].

MiR-214 inhibits bone formation by silencing activating transcription factor 4 (ATF4). In mouse preosteoblast 
MC3T3-E1 cells, with the treatment of miR-214 agonist, the levels of collagen I and ALP are significantly increased, showing the negative role of miR-214 in osteoblasts differentiation [112]. Meanwhile, miR-214 has been reported to enhance osteoclasts genesis from bone marrow monocytes (BMMs) via acting on PI3K/Akt pathway [106].

\section{Current Biomarkers for Osteoporosis Treatment}

In clinical setting, the established tools for evaluation of osteoporosis and bone fragility are bone mineral density assessment by Dual-X ray absorptiometry (DXA) and Fracture Risk Assessment Tool (FRAX), respectively [113]. However, DXA has several limitations. One limitation is that the assessment of BMD by DXA is based on the $2 \mathrm{D}$, instead of $3 \mathrm{D}$, images. The bone tissue properties, such as bone microstructure, which is essential for bone strength, cannot be measured by DXA. DXA also has quality control issues concerning errors from axial asymmetry of cross sections, assumptions used in calculating buckling ratios, and tissue mineralization assumption [114]. Meanwhile, since FRAX values the fracture risk with BMD criteria, it is not suitable for patients at high risk but without an osteoporotic BMD [115]. The risk of fracture is also influenced by other factors such as muscle function and the probability to fall. The parameters for evaluation of bone metabolism, such as beta C-terminal telopeptide (beta-CTX) and procollagen type I Npropeptide (P1NP), are important to assess the bone turnover and the response of the patients by the treatment. However, those parameters are not specific and not quite stable in the serum [116]. A single measurement of bone turnover could not estimate an absolute rate of bone loss. Moreover, they are not sensitive markers to reflect the bone fragility for those postmenopausal osteoporosis patients. It is, therefore, important to explore those stable biomarkers in the serum, which may be used for the detection of high risk of fracture in those postmenopausal osteoporosis patients. miRNAs are validated to be stable under harsh conditions including boiling, acid/alkaline circumstance, and freeze-thaw cycles with the help of high-density lipoproteins, which protectively bound to miRNAs from external RNases digestion [117]. Lipo-bound miRNAs are transported from the donor cells to the recipient cells by exosomes [118]. Meanwhile, the expression levels of serum miRNAs are reproducible and consistent among individuals [119], indicating that serum miRNAs could be suitable candidates for biomarkers in patients with osteoporosis.

\section{The Potential Role of miRNAs as Therapeutic Targets}

miRNAs have become an important therapeutic target for new drug research and development including analogs of miRNAs to enhance effectiveness and antagonist of miRNAs to interfere regulation, with advantages such as overcoming chemotherapy resistance, high efficiency, and low toxicity [120]. Clinical trial has been established in stage III colon cancer patients to study the anticancer effect by altering the binding capability of miRNA lethal-7 to Kirsten rat sarcoma viral oncogene homolog (KRAS) gene [121]. MiR122 is an important target for the clinical study in hepatitis $\mathrm{C}$ patients. Long-term safety and efficacy study confirmed the effectiveness of targeting miR-122 therapy [122, 123]. Currently, clinical research on miRNAs involved in bone metabolism is still at the inception phase. In vitro and in vivo studies have shown a prospect on the clinical application of miRNAs for the treatment of osteoporosis. For example, miR21 functionalized Ti implant could promote osteogenesis of BMSCs, which may provide a potential design for clinical use [124]. MiR-223 is reported to be an effective therapeutic target to relieve advanced glycation end products-induced damage to osteoblasts in diabetes mellitus [125]. MiR-150 could promote bone formation; the agomir of miR-150 may be considered as a novel therapy for osteoporosis [126]. MiR214 is a key regulator of osteoclast differentiation, which may be considered as a promising therapeutic target for osteoporosis [106]. However, the major concern for the application of miRNAs in osteoporosis treatment is the difficulty in delivering miRNA into the cells, which has a great impact on the efficacy of miRNAs.

\section{MicroRNAs Expression Profiles and Perspectives as Biomarkers in Osteoporosis}

As the evidence for the important role of miRNAs in the regulatory of bone remodeling is increasing, the association between miRNAs and bone loss disorders such as OP has been investigated by several groups. On one hand, the expression profile of serum miRNAs in the postmenopausal women has been studied. For instance, the expression of miR-422a and miR-133a in the serum is significantly different between postmenopausal women with low bone mineral density (BMD) and those with high BMD [127, 128]. The expression of miR-21 is significantly higher in the serum in OP patients compared to the control [129]. On the other hand, the expression profile of miRNAs in the patients with osteoporotic fractures has been investigated. For example, Panach et al. examined the plasma microRNAs from postmenopausal women with or without osteoporotic hip fractures and found that miR-122-5p, miR-125b-5p, and miR-21-5p were significantly upregulated in the patients with osteoporotic hip fractures compared to those without osteoporotic hip fractures [130]. This work is consistent with the previous work published by Seeliger et al., who demonstrated the significantly different expression level of miR-21, miR-23a, miR-24, miR-25, miR-100, and miR-125b in patients with hip fracture [131].

Our research group has also explored the expression profile of serum miRNAs in the postmenopausal osteoporotic women with or without vertebral fractures and the control. We have found that several miRNAs such as miR-106b and miR-19b were significantly different either between OP group and control or between OP with vertebral fracture group and the control group (Figure 2). 

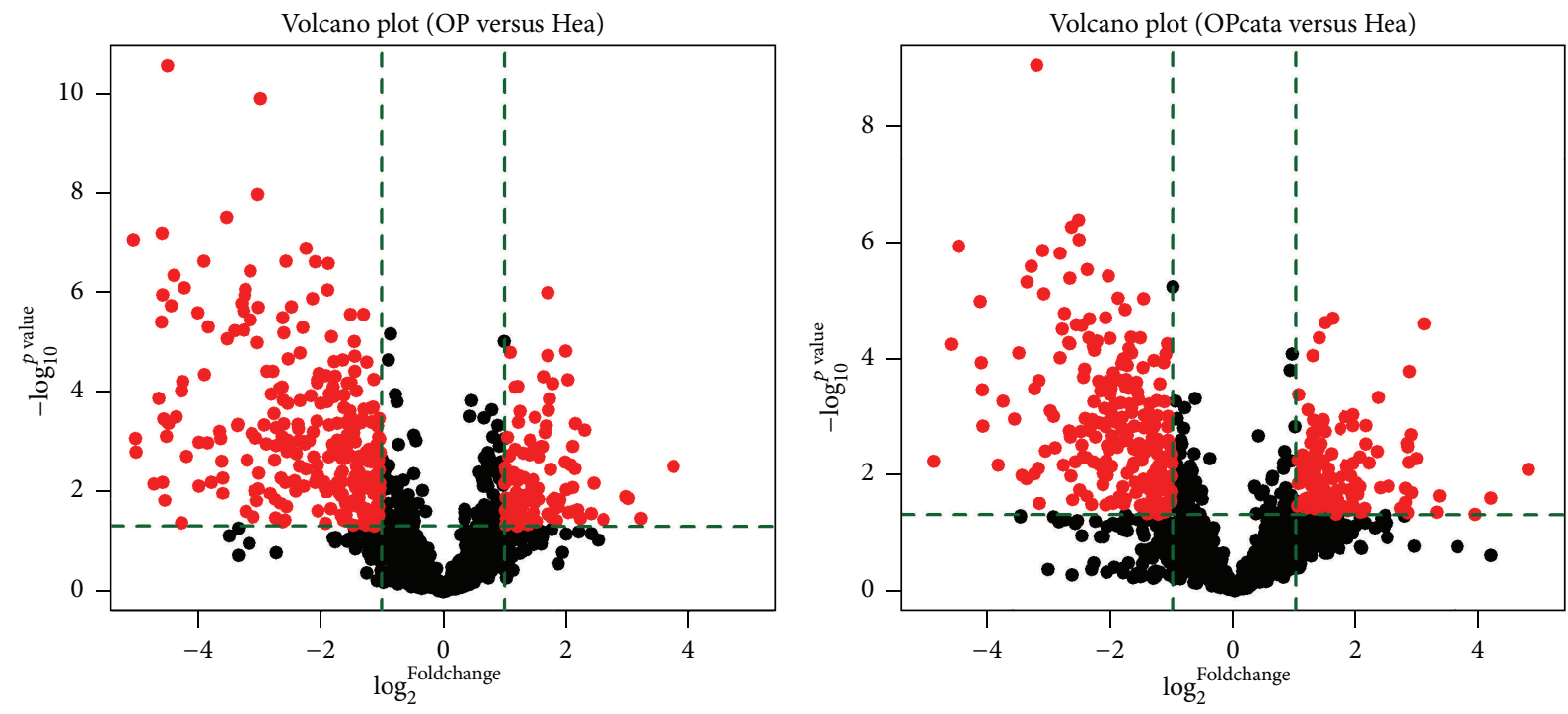

Figure 2: The volcano plot of miRNAs within each group. The red dots represent the miRNAs which were significantly differently expressed with $p$ values $<0.05$ and foldchange values $\geq 2$ or $\leq 0.5$.

\section{Summary and Future Directions}

miRNAs are endogenous molecules in our body and possess specific properties including easy access, high stability, tissue specificity, and significant sensitivity. They target specific genes and emerge in bone resorption and formation. This is also associated with many bone disorders. However, the mechanism and potential application still remain elusive. To elucidate this, there is at least three important points to be identified and clarified. Firstly, what are the specific miRNAs in bone remodeling? It is necessary to distinguish two groups of miRNAs involved in bone resorption and formation, respectively. This will pave important way for further study. Secondly, what is the significant expression level in the bone remodeling? miRNA is always minimally expressed and it has not been quantified to be in standard. Thirdly, how to detect the key miRNAs in bone tissue? Combined with biochemistry and special molecular technology, it is feasible to identify the expression profile of miRNA in peripheral circulation; however, further consideration is needed to implement the detection in bone tissue. Altogether, the miRNA will propose novel understanding for the bone biology and treatment.

\section{Disclosure}

Shishu Huang is a co-corresponding author of this paper.

\section{Competing Interests}

The authors declare that they have no competing interests.

\section{Acknowledgments}

This work was supported by the Natural Science Foundation of China (81371989 and 81472078), Strategic Emerging Industries of Shenzhen Research Project (JCYJ20130402103240488),
Shenzhen Peacock Innovation Team (110811003586331), and Shenzhen Science and Technology Innovation Committee Projects (S20140311220742, S20140317221322, and CXZZ20151015151249563).

\section{References}

[1] J. R. Czochor and P. M. Glazer, "MicroRNAs in cancer cell response to ionizing radiation," Antioxidants and Redox Signaling, vol. 21, no. 2, pp. 293-312, 2014.

[2] A. Esquela-Kerscher and F. J. Slack, "Oncomirs-MicroRNAs with a role in cancer," Nature Reviews Cancer, vol. 6, no. 4, pp. 259-269, 2006.

[3] M. V. Joglekar, V. M. Joglekar, and A. A. Hardikar, "Expression of islet-specific microRNAs during human pancreatic development," Gene Expression Patterns, vol. 9, no. 2, pp. 109-113, 2009.

[4] N. Khoshgoo, R. Kholdebarin, B. M. Iwasiow, and R. Keijzer, "MicroRNAs and lung development," Pediatric Pulmonology, vol. 48, no. 4, pp. 317-323, 2013.

[5] C. H. Lawrie, "MicroRNAs in hematological malignancies," Blood Reviews, vol. 27, no. 3, pp. 143-154, 2013.

[6] I. G. Papaconstantinou, P. M. Lykoudis, M. Gazouli, A. Manta, G. Polymeneas, and D. Voros, "A review on the role of MicroRNA in biology, diagnosis, and treatment of pancreatic adenocarcinoma," Pancreas, vol. 41, no. 5, pp. 671-677, 2012.

[7] H. Zhan, C. Cardozo, and A. Raza, "MicroRNAs in myeloproliferative neoplasms," British Journal of Haematology, vol. 161, no. 4, pp. 471-483, 2013.

[8] Y. Tutar, "miRNA and cancer; computational and experimental approaches," Current Pharmaceutical Biotechnology, vol. 15, no. 5, p. 429, 2014.

[9] R. J. Farr, M. V. Joglekar, and A. A. Hardikar, "Circulating microRNAs in diabetes progression: discovery, validation, and research translation," in Circulating microRNAs in Disease Diagnostics and Their Potential Biological Relevance, vol. 106 of Experientia Supplementum, pp. 215-244, Springer, Basel, Switzerland, 2015. 
[10] M. Grasso, P. Piscopo, A. Crestini, A. Confaloni, and M. A. Denti, "Circulating microRNAs in neurodegenerative diseases," in Circulating microRNAs in Disease Diagnostics and their Potential Biological Relevance, P. Igaz, Ed., vol. 106 of Experientia Supplementum, pp. 151-169, 2015.

[11] N. H. Heegaard, A. L. Carlsen, K. Skovgaard, and P. M. Heegaard, "Circulating extracellular microRNA in systemic autoimmunity," EXS, vol. 106, pp. 171-195, 2015.

[12] S. De Rosa and C. Indolfi, "Circulating microRNAs as biomarkers in cardiovascular diseases," in Circulating microRNAs in Disease Diagnostics and Their Potential Biological Relevance, vol. 106 of Experientia Supplementum, pp. 139-149, Springer, Basel, Switzerland, 2015.

[13] P. Tang, Q. Xiong, W. Ge, and L. Zhang, "The role of microRNAs in osteoclasts and osteoporosis," RNA Biology, vol. 11, no. 11, pp. 1355-1363, 2014.

[14] X. Zhao, D. Xu, Y. Li et al., "MicroRNAs regulate bone metabolism," Journal of Bone and Mineral Metabolism, vol. 32, no. 3, pp. 221-231, 2014.

[15] V. Lemaire, F. L. Tobin, L. D. Greller, C. R. Cho, and L. J. Suva, "Modeling the interactions between osteoblast and osteoclast activities in bone remodeling," Journal of Theoretical Biology, vol. 229, no. 3, pp. 293-309, 2004.

[16] Y. Xie, L. Zhang, Y. Gao, W. Ge, and P. Tang, "The multiple roles of microrna-223 in regulating bone metabolism," Molecules, vol. 20, no. 10, pp. 19433-19448, 2015.

[17] B. Zuo, J. Zhu, J. Li et al., "microRNA-103a functions as a mechanosensitive microRNA to inhibit bone formation through targeting Runx2," Journal of Bone and Mineral Research, vol. 30, no. 2, pp. 330-345, 2015.

[18] J. A. Riancho and J. L. Hernández, "Pharmacogenomics of osteoporosis: a pathway approach," Pharmacogenomics, vol. 13, no. 7, pp. 815-829, 2012.

[19] A. R. Hayman, "Tartrate-resistant acid phosphatase (TRAP) and the osteoclast/immune cell dichotomy," Autoimmunity, vol. 41, no. 3, pp. 218-223, 2008.

[20] S. Granholm, P. Lundberg, and U. H. Lerner, "Expression of the calcitonin receptor, calcitonin receptor-like receptor, and receptor activity modifying proteins during osteoclast differentiation," Journal of Cellular Biochemistry, vol. 104, no. 3, pp. 920-933, 2008.

[21] J. Ljusberg, Y. Wang, P. Lång et al., "Proteolytic excision of a repressive loop domain in tartrate-resistant acid phosphatase by cathepsin K in osteoclasts," The Journal of Biological Chemistry, vol. 280, no. 31, pp. 28370-28381, 2005.

[22] O. Ishibashi, S. Niwa, K. Kadoyama, and T. Inui, "MMP-9 antisense oligodeoxynucleotide exerts an inhibitory effect on osteoclastic bone resorption by suppressing cell migration," Life Sciences, vol. 79, no. 17, pp. 1657-1660, 2006.

[23] S. Takayama, S. Ishii, T. Ikeda, S. Masamura, M. Doi, and M. Kitajima, "The relationship between bone metastasis from human breast cancer and integrin $\alpha \mathrm{v} \beta 3$ expression," Anticancer Research, vol. 25, no. 1, pp. 79-83, 2005.

[24] M. N. Weitzmann, "The role of inflammatory cytokines, the RANKL/OPG axis, and the immunoskeletal interface in physiological bone turnover and osteoporosis," Scientifica, vol. 2013, Article ID 125705, 29 pages, 2013.

[25] T. Yamashita, Z. Yao, F. Li et al., "NF- $\kappa$ B p50 and p52 regulate receptor activator of NF- $\kappa$ B ligand (RANKL) and tumor necrosis factor-induced osteoclast precursor differentiation by activating c-Fos and NFATc1," Journal of Biological Chemistry, vol. 282, no. 25 , pp. 18245-18253, 2007.
[26] D. G. Monroe, M. E. McGee-Lawrence, M. J. Oursler, and J. J. Westendorf, "Update on Wnt signaling in bone cell biology and bone disease," Gene, vol. 492, no. 1, pp. 1-18, 2012.

[27] B. O. Williams and K. L. Insogna, "Where Wnts went: the exploding field of Lrp5 and Lrp6 signaling in bone," Journal of Bone and Mineral Research, vol. 24, no. 2, pp. 171-178, 2009.

[28] Y. Gong, R. B. Slee, N. Fukai et al., "LDL receptor-related protein 5 (LRP5) affects bone accrual and eye development," Cell, vol. 107, no. 4, pp. 513-523, 2001.

[29] M. P. Whyte, W. H. Reinus, and S. Mumm, "High-bone-mass disease and LRP5," The New England Journal of Medicine, vol. 350, no. 20, pp. 2096-2096, 2004.

[30] T. Jin, I. G. Fantus, and J. Sun, "Wnt and beyond Wnt: multiple mechanisms control the transcriptional property of $\beta$-catenin," Cellular Signalling, vol. 20, no. 10, pp. 1697-1704, 2008.

[31] D. A. Glass II, P. Bialek, J. D. Ahn et al., "Canonical Wnt signaling in differentiated osteoblasts controls osteoclast differentiation," Developmental Cell, vol. 8, no. 5, pp. 751-764, 2005.

[32] Y.-W. Qiang, Y. Chen, O. Stephens et al., "Myeloma-derived dickkopf-1 disrupts Wnt-regulated osteoprotegerin and RANKL production by osteoblasts: a potential mechanism underlying osteolytic bone lesions in multiple myeloma," Blood, vol. 112, no. 1, pp. 196-207, 2008.

[33] M. Rossini, D. Gatti, and S. Adami, "Involvement of WNT/ $\beta$ catenin signaling in the treatment of osteoporosis," Calcified Tissue International, vol. 93, no. 2, pp. 121-132, 2013.

[34] M. P. Playford, D. Bicknell, W. F. Bodmer, and V. M. Macaulay, "Insulin-like growth factor 1 regulates the location, stability, and transcriptional activity of $\beta$-catenin," Proceedings of the National Academy of Sciences of the United States of America, vol. 97, no. 22, pp. 12103-12108, 2000.

[35] V. Deregowski, E. Gazzerro, L. Priest, S. Rydziel, and E. Canalis, "Notch 1 overexpression inhibits osteoblastogenesis by suppressing Wnt/ $\beta$-catenin but not bone morphogenetic protein signaling," Journal of Biological Chemistry, vol. 281, no. 10, pp. 6203-6210, 2006.

[36] X. Li, Y. Zhang, H. Kang et al., "Sclerostin binds to LRP5/6 and antagonizes canonical Wnt signaling," Journal of Biological Chemistry, vol. 280, no. 20, pp. 19883-19887, 2005.

[37] T. Katagiri and S. Tsukamoto, "The unique activity of bone morphogenetic proteins in bone: a critical role of the Smad signaling pathway," Biological Chemistry, vol. 394, no. 6, pp. 703-714, 2013.

[38] S.-I. Harada and G. A. Rodan, "Control of osteoblast function and regulation of bone mass," Nature, vol. 423, no. 6937, pp. 349355, 2003.

[39] M. F. Hagh, M. Noruzinia, Y. Mortazavi et al., "Different methylation patterns of RUNX2, OSX, DLX5 and BSP in osteoblastic differentiation of mesenchymal stem cells," Cell Journal, vol. 17, no. 1, pp. 71-82, 2015.

[40] M.-H. Ho, C.-J. Yao, M.-H. Liao, P.-I. Lin, S.-H. Liu, and R.M. Chen, "Chitosan nanofiber scaffold improves bone healing via stimulating trabecular bone production due to upregulation of the Runx2/osteocalcin/alkaline phosphatase signaling pathway," International Journal of Nanomedicine, vol. 10, pp. 5941$5954,2015$.

[41] J.-C. Xi, H.-Y. Zang, L.-X. Guo et al., "The PI3K/AKT cell signaling pathway is involved in regulation of osteoporosis," Journal of Receptors and Signal Transduction, vol. 35, no. 6, pp. 640-645, 2015. 
[42] T. Matsubara, K. Kida, A. Yamaguchi et al., "BMP2 regulates osterix through Msx2 and Runx2 during osteoblast differentiation," The Journal of Biological Chemistry, vol. 283, no. 43, pp. 29119-29125, 2008.

[43] X. Zhang, J. Akech, G. Browne et al., "Runx2-Smad signaling impacts the progression of tumor-induced bone disease," International Journal of Cancer, vol. 136, no. 6, pp. 1321-1332, 2015.

[44] P. Maroni, A. T. Brini, E. Arrigoni et al., "Chemical and genetic blockade of HDACs enhances osteogenic differentiation of human adipose tissue-derived stem cells by oppositely affecting osteogenic and adipogenic transcription factors," Biochemical and Biophysical Research Communications, vol. 428, no. 2, pp. 271-277, 2012.

[45] H. Guo and A. D. Friedman, "Phosphorylation of RUNX1 by cyclin-dependent kinase reduces direct interaction with HDAC1 and HDAC3," Journal of Biological Chemistry, vol. 286, no. 1, pp. 208-215, 2011.

[46] E.-J. Jeon, K.-Y. Lee, N.-S. Choi et al., "Bone morphogenetic protein-2 stimulates Runx2 acetylation," Journal of Biological Chemistry, vol. 281, no. 24, pp. 16502-16511, 2006.

[47] Z. Jin, W. Wei, H. Huynh, and Y. Wan, "HDAC9 inhibits osteoclastogenesis via mutual suppression of PPAR $\gamma /$ RANKL signaling," Molecular Endocrinology, vol. 29, no. 5, pp. 730-738, 2015.

[48] A. Javed, H. Chen, and F. Y. Ghori, "Genetic and transcriptional control of bone formation," Oral and Maxillofacial Surgery Clinics of North America, vol. 22, no. 3, pp. 283-293, 2010.

[49] M. Q. Hassan, R. Tare, S. H. Lee et al., "HOXA10 controls osteoblastogenesis by directly activating bone regulatory and phenotypic genes," Molecular and Cellular Biology, vol. 27, no. 9, pp. 3337-3352, 2007.

[50] J.-B. Kim, P. Leucht, C. A. Luppen et al., "Reconciling the roles of FAK in osteoblast differentiation, osteoclast remodeling, and bone regeneration," Bone, vol. 41, no. 1, pp. 39-51, 2007.

[51] C.-Z. Chen, L. Li, H. F. Lodish, and D. P. Bartel, "MicroRNAs modulate hematopoietic lineage differentiation," Science, vol. 303, no. 5654, pp. 83-86, 2004.

[52] L. Tuddenham, G. Wheeler, S. Ntounia-Fousara et al., "The cartilage specific microRNA-140 targets histone deacetylase 4 in mouse cells," FEBS Letters, vol. 580, no. 17, pp. 4214-4217, 2006.

[53] H. I. Roach, "Why does bone matrix contain non-collagenous proteins? The possible roles of osteocalcin, osteonectin, osteopontin and bone sialoprotein in bone mineralisation and resorption," Cell Biology International, vol. 18, no. 6, pp. 617-628, 1994.

[54] A. Azizian, F. Kramer, P. Jo et al., "Preoperative prediction of lymph node status by circulating MIR-18b and MIR-20a during chemoradiotherapy in patients with rectal cancer," World Journal of Surgery, vol. 39, no. 9, pp. 2329-2335, 2015.

[55] K. R. Babu and M. U. Muckenthaler, "miR-20a regulates expression of the iron exporter ferroportin in lung cancer," Journal of Molecular Medicine, 2015.

[56] Y. du, M. Zhu, X. Zhou et al., "miR-20a enhances cisplatin resistance of human gastric cancer cell line by targeting NFKBIB," Tumor Biology, 2015.

[57] A. Safari, M. Seifoleslami, E. Yahaghi, F. Sedaghati, and M. K. Khameneie, "Upregulation of miR-20a and miR-10a expression levels act as potential biomarkers of aggressive progression and poor prognosis in cervical cancer," Tumor Biology, pp. 1-5, 2015.

[58] D. M. Tiago, C. L. Marques, V. P. Roberto, M. L. Cancela, and V. Laizé, "Mir-20a regulates in vitro mineralization and
BMP signaling pathway by targeting BMP-2 transcript in fish," Archives of Biochemistry and Biophysics, vol. 543, pp. 23-30, 2014.

[59] J.-F. Zhang, W.-M. Fu, M.-L. He et al., "MiRNA-20a promotes osteogenic differentiation of human mesenchymal stem cells by co-regulating BMP signaling," RNA Biology, vol. 8, no. 5, pp. 829-838, 2011.

[60] C. Shi, J. Qi, P. Huang et al., "MicroRNA-17/20a inhibits glucocorticoid-induced osteoclast differentiation and function through targeting RANKL expression in osteoblast cells," Bone, vol. 68, pp. 67-75, 2014.

[61] Y. Singh, O. A. Garden, F. Lang, and B. S. Cobb, "MicroRNA$15 \mathrm{~b} / 16$ enhances the induction of regulatory $\mathrm{T}$ cells by regulating the expression of rictor and mTOR," The Journal of Immunology, vol. 195, no. 12, pp. 5667-5677, 2015.

[62] L. H. Oliveira, J. L. Schiavinato, M. S. Fráguas et al., "Potential roles of microRNA-29a in the molecular pathophysiology of Tcell acute lymphoblastic leukemia," Cancer Science, vol. 106, pp. 1264-1277, 2015.

[63] P. Patel, M. Y. Ansari, S. Bapat, M. Thakar, R. Gangakhedkar, and S. Jameel, "The microRNA miR-29a is associated with human immunodeficiency virus latency," Retrovirology, vol. 11, no. 1, article 108, 2014.

[64] Y. Zhou, L. Sun, X. Wang et al., "HIV-1 infection suppresses circulating viral restriction microRNAs," AIDS Research and Human Retroviruses, 2015.

[65] F.-S. Wang, P.-C. Chung, C.-L. Lin et al., "MicroRNA-29a protects against glucocorticoid-induced bone loss and fragility in rats by orchestrating bone acquisition and resorption," Arthritis and Rheumatism, vol. 65, no. 6, pp. 1530-1540, 2013.

[66] J.-Y. Ko, P.-C. Chuang, M.-W. Chen et al., "MicroRNA-29a ameliorates glucocorticoid-induced suppression of osteoblast differentiation by regulating $\beta$-catenin acetylation," Bone, vol. 57, no. 2, pp. 468-475, 2013.

[67] W.-J. Yoon, Y.-D. Cho, W.-J. Kim et al., "Prolyl isomerase Pinl-mediated conformational change and subnuclear focal accumulation of Runx 2 are crucial for fibroblast growth factor 2 (FGF2)-induced osteoblast differentiation," The Journal of Biological Chemistry, vol. 289, no. 13, pp. 8828-8838, 2014.

[68] J.-Y. Ko, P.-C. Chuang, H.-J. Ke, Y.-S. Chen, Y.-C. Sun, and F.S. Wang, "MicroRNA-29a mitigates glucocorticoid induction of bone loss and fatty marrow by rescuing Runx 2 acetylation," Bone, vol. 81, pp. 80-88, 2015.

[69] H. Xia, Y. Qi, S. S. Ng et al., "MicroRNA-15b regulates cell cycle progression by targeting cyclins in glioma cells," Biochemical and Biophysical Research Communications, vol. 380, no. 2, pp. 205-210, 2009.

[70] N. H. Fleming, J. Zhong, I. P. da Silva et al., "Serum-based miRNAs in the prediction and detection of recurrence in melanoma patients," Cancer, vol. 121, no. 1, pp. 51-59, 2015.

[71] H. Sun, X. Meng, J. Han et al., "Anti-cancer activity of DHA on gastric cancer-an in vitro and in vivo study," Tumor Biology, vol. 34, no. 6, pp. 3791-3800, 2013.

[72] S. Vimalraj, N. C. Partridge, and N. Selvamurugan, "A positive role of microRNA-15b on regulation of osteoblast differentiation," Journal of Cellular Physiology, vol. 229, no. 9, pp. 12361244, 2014.

[73] R. Sainitya, M. Sriram, V. Kalyanaraman et al., "Scaffolds containing chitosan/carboxymethyl cellulose/mesoporous wollastonite for bone tissue engineering," International Journal of Biological Macromolecules, vol. 80, pp. 481-488, 2015. 
[74] V. Bodempudi, P. Hergert, K. Smith et al., "miR-210 promotes IPF fibroblast proliferation in response to hypoxia," American Journal of Physiology-Lung Cellular and Molecular Physiology, vol. 307, no. 4, pp. L283-L294, 2014.

[75] T. Rosenberg, M. Thomassen, S. S. Jensen et al., "Acute hypoxia induces upregulation of microRNA-210 expression in glioblastoma spheroids," CNS Oncology, vol. 4, no. 1, pp. 25-35, 2015.

[76] S. Guo, R. Bai, W. Liu et al., "MicroRNA-210 is upregulated by hypoxia-inducible factor- $1 \alpha$ in the stromal cells of giant cell tumors of bone," Molecular Medicine Reports, vol. 12, no. 4, pp. 6185-6192, 2015.

[77] X.-D. Liu, F. Cai, L. Liu, Y. Zhang, and A.-L. Yang, "MicroRNA210 is involved in the regulation of postmenopausal osteoporosis through promotion of VEGF expression and osteoblast differentiation," Biological Chemistry, vol. 396, no. 4, pp. 339347, 2015.

[78] Y. Mizuno, Y. Tokuzawa, Y. Ninomiya et al., "miR-210 promotes osteoblastic differentiation through inhibition of AcvR1b," FEBS Letters, vol. 583, no. 13, pp. 2263-2268, 2009.

[79] B. Hou, Z. Jian, S. Chen, Y. Ou, S. Li, and J. Ou, "Expression of miR-216a in pancreatic cancer and its clinical significance," Journal of Southern Medical University, vol. 32, no. 11, pp. 16281631, 2012.

[80] B.-H. Hou, Z.-X. Jian, P. Cui, S.-J. Li, R.-Q. Tian, and J.-R. Ou, "MIR-216a may inhibit pancreatic tumor growth by targeting JAK2," FEBS Letters, vol. 589, no. 17, pp. 2224-2232, 2015.

[81] Y. Wang, Y. Zhao, and L. Ge, "Effects of the enamel matrix derivative on the proliferation and odontogenic differentiation of human dental pulp cells," Journal of Dentistry, vol. 42, no. 1, pp. 53-59, 2014.

[82] H. Li, T. Li, J. Fan et al., "miR-216a rescues dexamethasone suppression of osteogenesis, promotes osteoblast differentiation and enhances bone formation, by regulating c-Cbl-mediated PI3K/AKT pathway," Cell Death and Differentiation, vol. 22, no. 12, pp. 1935-1945, 2015.

[83] H. Li, H. Xie, W. Liu et al., "A novel microRNA targeting HDAC5 regulates osteoblast differentiation in mice and contributes to primary osteoporosis in humans," Journal of Clinical Investigation, vol. 119, no. 12, pp. 3666-3677, 2009.

[84] R. Hu, W. Liu, H. Li et al., "A Runx2/miR-3960/miR-2861 regulatory feedback loop during mouse osteoblast differentiation," The Journal of Biological Chemistry, vol. 286, no. 14, pp. 1232812339, 2011.

[85] Z.-Y. Xia, Y. Hu, P.-L. Xie et al., "Runx2/miR-3960/miR-2861 positive feedback loop is responsible for osteogenic transdifferentiation of vascular smooth muscle cells," BioMed Research International, vol. 2015, Article ID 624037, 7 pages, 2015.

[86] J. Huang, L. Zhao, L. Xing, and D. Chen, "MicroRNA-204 regulates Runx2 protein expression and mesenchymal progenitor cell differentiation," Stem Cells, vol. 28, no. 2, pp. 357-364, 2010.

[87] M.-Y. Song, J.-Z. Yu, D.-M. Zhao et al., "The time-dependent manner of sinusoidal electromagnetic fields on rat bone marrow mesenchymal stem cells proliferation, differentiation, and mineralization," Cell Biochemistry and Biophysics, vol. 69, no. 1, pp. 47-54, 2014.

[88] L. Liao, X. Yang, X. Su et al., "Redundant miR-3077-5p and miR-705 mediate the shift of mesenchymal stem cell lineage commitment to adipocyte in osteoporosis bone marrow," Cell Death and Disease, vol. 4, no. 4, article e600, 2013.

[89] H. Liu, Q. Sun, C. Wan, L. Li, L. Zhang, and Z. Chen, "MicroRNA-338-3p regulates osteogenic differentiation of mouse bone marrow stromal stem cells by targeting Runx 2 and Fgfr2," Journal of Cellular Physiology, vol. 229, no. 10, pp. 14941502, 2014.

[90] D. W. Guo, Y. X. Han, L. Cong, D. Liang, and G. J. Tu, "Resveratrol prevents osteoporosis in ovariectomized rats by regulating microRNA-338-3p," Molecular Medicine Reports, vol. 12, pp. 2098-20106, 2015.

[91] S. Chen, L. Yang, Q. Jie et al., "MicroRNA-125b suppresses the proliferation and osteogenic differentiation of human bone marrow-derived mesenchymal stem cells," Molecular Medicine Reports, vol. 9, no. 5, pp. 1820-1826, 2014.

[92] J.-F. Zhang, W.-M. Fu, M.-L. He et al., "MiR-637 maintains the balance between adipocytes and osteoblasts by directly targeting Osterix," Molecular Biology of the Cell, vol. 22, no. 21, pp. 3955-3961, 2011.

[93] C.-J. Li, P. Cheng, M.-K. Liang et al., "MicroRNA-188 regulates age-related switch between osteoblast and adipocyte differentiation," The Journal of Clinical Investigation, vol. 125, no. 4, pp. 1509-1522, 2015.

[94] W. Qiu and M. Kassem, "MiR-141-3p inhibits human stromal (mesenchymal) stem cell proliferation and differentiation," Biochimica et Biophysica Acta-Molecular Cell Research, vol. 1843, no. 9, pp. 2114-2121, 2014.

[95] T. Eskildsen, H. Taipaleenmäki, J. Stenvang et al., "MicroRNA138 regulates osteogenic differentiation of human stromal (mesenchymal) stem cells in vivo," Proceedings of the National Academy of Sciences of the United States of America, vol. 108, no. 15, pp. 6139-6144, 2011.

[96] T. Sun, F. Leung, and W. W. Lu, "miR-9-5p, miR-675-5p and miR-138-5p damages the strontium and LRP5-mediated skeletal cell proliferation, differentiation, and adhesion," International Journal of Molecular Sciences, vol. 17, no. 2, p. 236, 2016.

[97] C. Chen, P. Cheng, H. Xie et al., "MiR-503 regulates osteoclastogenesis via targeting RANK," Journal of Bone and Mineral Research, vol. 29, no. 2, pp. 338-347, 2014.

[98] P. Cheng, C. Chen, H.-B. He et al., "MiR-148a regulates osteoclastogenesis by targeting V-maf musculoaponeurotic fibrosarcoma oncogene homolog B," Journal of Bone and Mineral Research, vol. 28, no. 5, pp. 1180-1190, 2013.

[99] S. Wang, C. Tang, Q. Zhang, and W. Chen, "Reduced miR-9 and miR-181a expression down-regulates Bim concentration and promote osteoclasts survival," International Journal of Clinical and Experimental Pathology, vol. 7, no. 5, pp. 2209-2218, 2014.

[100] B. Shao, L. Liao, Y. Yu et al., "Estrogen preserves Fas ligand levels by inhibiting microRNA-181a in bone marrow-derived mesenchymal stem cells to maintain bone remodeling balance," The FASEB Journal, vol. 29, no. 9, pp. 3935-3944, 2015.

[101] Y. Bae, T. Yang, H.-C. Zeng et al., "miRNA-34c regulates Notch signaling during bone development," Human Molecular Genetics, vol. 21, no. 13, Article ID dds129, pp. 2991-3000, 2012.

[102] H. Li, T. Li, S. Wang et al., "MiR-17-5p and miR-106a are involved in the balance between osteogenic and adipogenic differentiation of adipose-derived mesenchymal stem cells," Stem Cell Research, vol. 10, no. 3, pp. 313-324, 2013.

[103] L. You, W. Gu, L. Chen, L. Pan, J. Chen, and Y. Peng, "MiR-378 overexpression attenuates high glucose-suppressed osteogenic differentiation through targeting CASP3 and activating PI3k/Akt signaling pathway," International Journal of Clinical and Experimental Pathology, vol. 7, no. 10, pp. 72497261, 2014. 
[104] E. Luzi, F. Marini, S. C. Sala, I. Tognarini, G. Galli, and M. L. Brandi, "Osteogenic differentiation of human adipose tissuederived stem cells is modulated by the miR-26a targeting of the SMAD1 transcription factor," Journal of Bone and Mineral Research, vol. 23, no. 2, pp. 287-295, 2008.

[105] J. Y. Krzeszinski, W. Wei, H. Huynh et al., "MiR-34a blocks osteoporosis and bone metastasis by inhibiting osteoclastogenesis and Tgif2," Nature, vol. 512, no. 7515, pp. 431-435, 2014.

[106] C. Zhao, W. Sun, P. Zhang et al., "miR-214 promotes osteoclastogenesis by targeting pten/pi3k/Akt pathway," RNA Biology, vol. 12, no. 3, pp. 343-353, 2015.

[107] K. Kim, J. H. Kim, I. Kim et al., "MicroRNA-26a regulates RANKL-induced osteoclast formation," Molecules and Cells, vol. 38, no. 1, pp. 75-80, 2015.

[108] M. Y. W. Wong, Y. Yu, W. R. Walsh, and J.-L. Yang, "microRNA34 family and treatment of cancers with mutant or wild-type p53 (Review)," International Journal of Oncology, vol. 38, no. 5, pp. 1189-1195, 2011.

[109] Y. He, L. F. de Castro, M. H. Shin et al., "P53 loss increases the osteogenic differentiation of bone marrow stromal cells," STEM CELLS, vol. 33, no. 4, pp. 1304-1319, 2015.

[110] Z. Wang, D. Zhang, Z. Hu et al., "MicroRNA-26a-modified adipose-derived stem cells incorporated with a porous hydroxyapatite scaffold improve the repair of bone defects," Molecular Medicine Reports, vol. 12, no. 3, pp. 3345-3350, 2015.

[111] X. Su, L. Liao, Y. Shuai et al., "MiR-26a functions oppositely in osteogenic differentiation of BMSCs and ADSCs depending on distinct activation and roles of Wnt and BMP signaling pathway," Cell Death and Disease, vol. 6, Article ID e1851, 2015.

[112] X. Wang, B. Guo, Q. Li et al., "MiR-214 targets ATF4 to inhibit bone formation," Nature Medicine, vol. 19, no. 1, pp. 93-100, 2013.

[113] S. L. Silverman and A. D. Calderon, "The utility and limitations of FRAX: a us perspective," Current Osteoporosis Reports, vol. 8, no. 4, pp. 192-197, 2010.

[114] T. Beck, "Measuring the structural strength of bones with dualenergy X-ray absorptiometry: principles, technical limitations, and future possibilities," Osteoporosis International, vol. 14, supplement 5, pp. 81-88, 2003.

[115] T. A. Hillier, J. A. Cauley, J. H. Rizzo et al., "WHO absolute fracture risk models (FRAX): do clinical risk factors improve fracture prediction in older women without osteoporosis?" Journal of Bone and Mineral Research, vol. 26, no. 8, pp. 17741782, 2011.

[116] P. Garnero and P. D. Delmas, "Contribution of bone mineral density and bone turnover markers to the estimation of risk of osteoporotic fracture in postmenopausal women," Journal of Musculoskeletal Neuronal Interactions, vol. 4, no. 1, pp. 50-63, 2004.

[117] K. C. Vickers, B. T. Palmisano, B. M. Shoucri, R. D. Shamburek, and A. T. Remaley, "MicroRNAs are transported in plasma and delivered to recipient cells by high-density lipoproteins," Nature Cell Biology, vol. 13, no. 4, pp. 423-433, 2011.

[118] H. Valadi, K. Ekström, A. Bossios, M. Sjöstrand, J. J. Lee, and J. O. Lötvall, "Exosome-mediated transfer of mRNAs and microRNAs is a novel mechanism of genetic exchange between cells," Nature Cell Biology, vol. 9, no. 6, pp. 654-659, 2007.

[119] X. Chen, Y. Ba, L. Ma et al., "Characterization of microRNAs in serum: a novel class of biomarkers for diagnosis of cancer and other diseases," Cell Research, vol. 18, no. 10, pp. 997-1006, 2008.

[120] A. Neesse and T. M. Gress, "Emerging role of microRNAs to tackle drug resistance in pancreatic cancer," Gut, vol. 64, pp. 1842-1843, 2015.
[121] D. Sha, A. M. Lee, Q. Shi et al., "Association study of the let7 miRNA-complementary site variant in the $3^{\prime}$ untranslated region of the KRAS gene in stage III colon cancer (NCCTG N0147 Clinical Trial)," Clinical Cancer Research, vol. 20, no. 12, pp. 3319-3327, 2014.

[122] M. H. van der Ree, A. J. van der Meer, J. de Bruijne et al., "Long-term safety and efficacy of microRNA-targeted therapy in chronic hepatitis C patients," Antiviral Research, vol. 111, pp. 53-59, 2014.

[123] C. D. Sedano and P. Sarnow, "Interaction of host cell microRNAs with the HCV RNA genome during infection of liver cells," Seminars in Liver Disease, vol. 35, no. 1, pp. 75-80, 2015.

[124] Z. Wang, G. Wu, Z. Feng et al., "Microarc-oxidized titanium surfaces functionalized with microRNA-21-loaded chitosan/hyaluronic acid nanoparticles promote the osteogenic differentiation of human bone marrow mesenchymal stem cells," International Journal of Nanomedicine, vol. 10, pp. 66756687, 2015.

[125] Y. Qin, J. Ye, P. Wang, L. Gao, S. Wang, and H. Shen, “miR-223 contributes to the AGE-promoted apoptosis via downregulating insulin-like growth factor 1 receptor in osteoblasts," Bioscience Reports, 2016.

[126] C.-L. Dong, H.-Z. Liu, Z.-C. Zhang et al., "The influence of MicroRNA-150 in osteoblast matrix mineralization," Journal of Cellular Biochemistry, vol. 116, no. 12, pp. 2970-2979, 2015.

[127] Z. Cao, B. T. Moore, Y. Wang et al., "MiR-422a as a potential cellular microRNA biomarker for postmenopausal osteoporosis," PLoS ONE, vol. 9, no. 5, Article ID e97098, 2014.

[128] Y. Wang, L. Li, B. T. Moore et al., "Mir-133a in human circulating monocytes: a potential biomarker associated with postmenopausal osteoporosis," PLoS ONE, vol. 7, no. 4, Article ID e34641, 2012.

[129] N. Yang, G. Wang, C. Hu et al., "Tumor necrosis factor $\alpha$ suppresses the mesenchymal stem cell osteogenesis promoter miR-21 in estrogen deficiency-induced osteoporosis," Journal of Bone and Mineral Research, vol. 28, no. 3, pp. 559-573, 2013.

[130] L. Panach, D. Mifsut, J. J. Tarín, A. Cano, and M. Á. GarcíaPérez, "Serum circulating MicroRNAs as biomarkers of osteoporotic fracture," Calcified Tissue International, vol. 97, no. 5, pp. 495-505, 2015.

[131] C. Seeliger, K. Karpinski, A. T. Haug et al., "Five freely circulating miRNAs and bone tissue miRNAs are associated with osteoporotic fractures," Journal of Bone and Mineral Research, vol. 29, no. 8, pp. 1718-1728, 2014. 

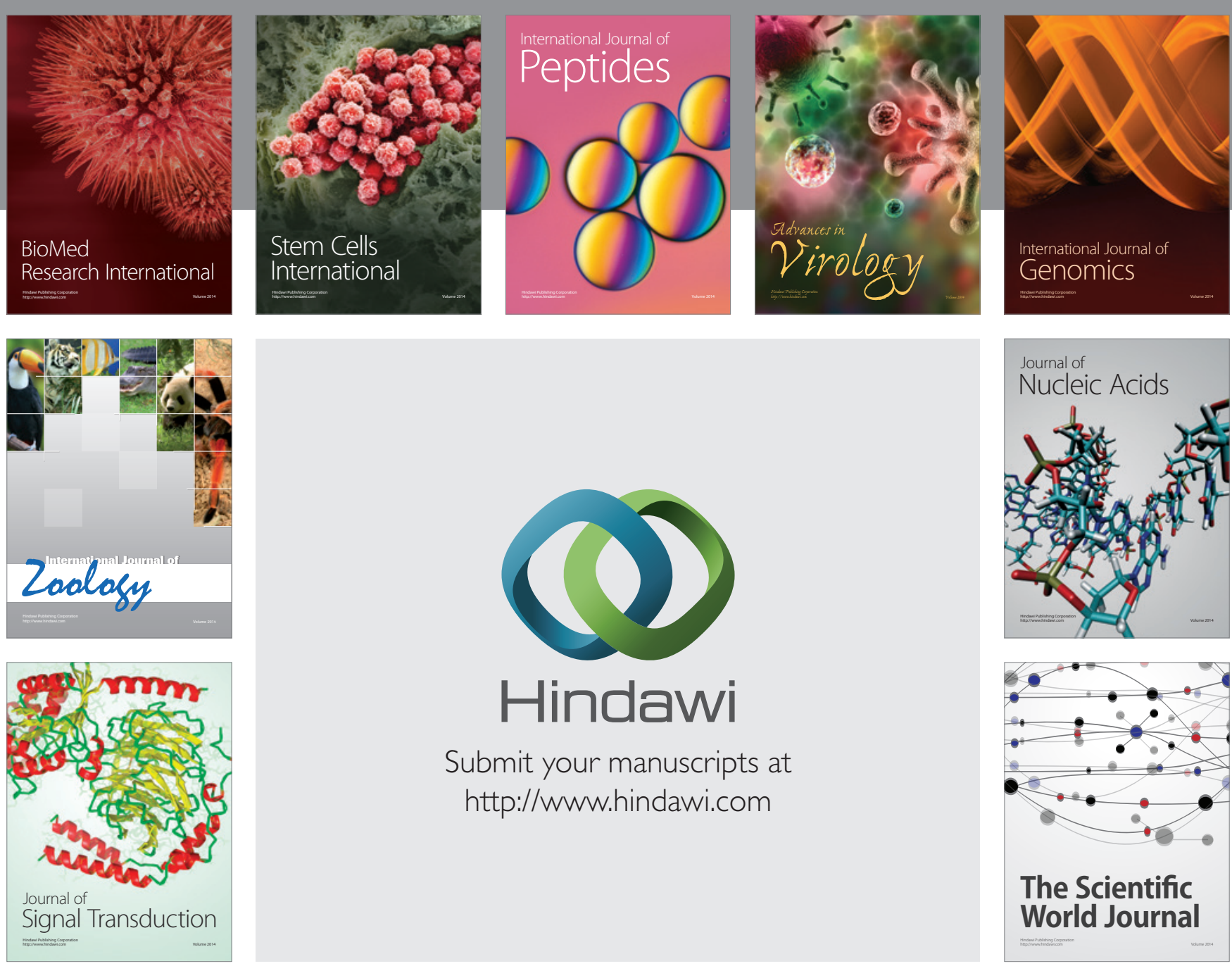

Submit your manuscripts at

http://www.hindawi.com
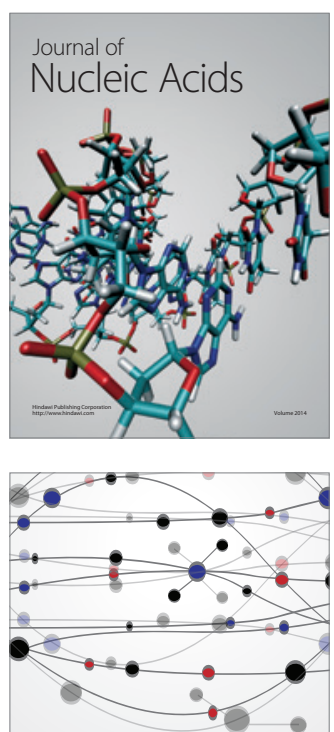

The Scientific World Journal
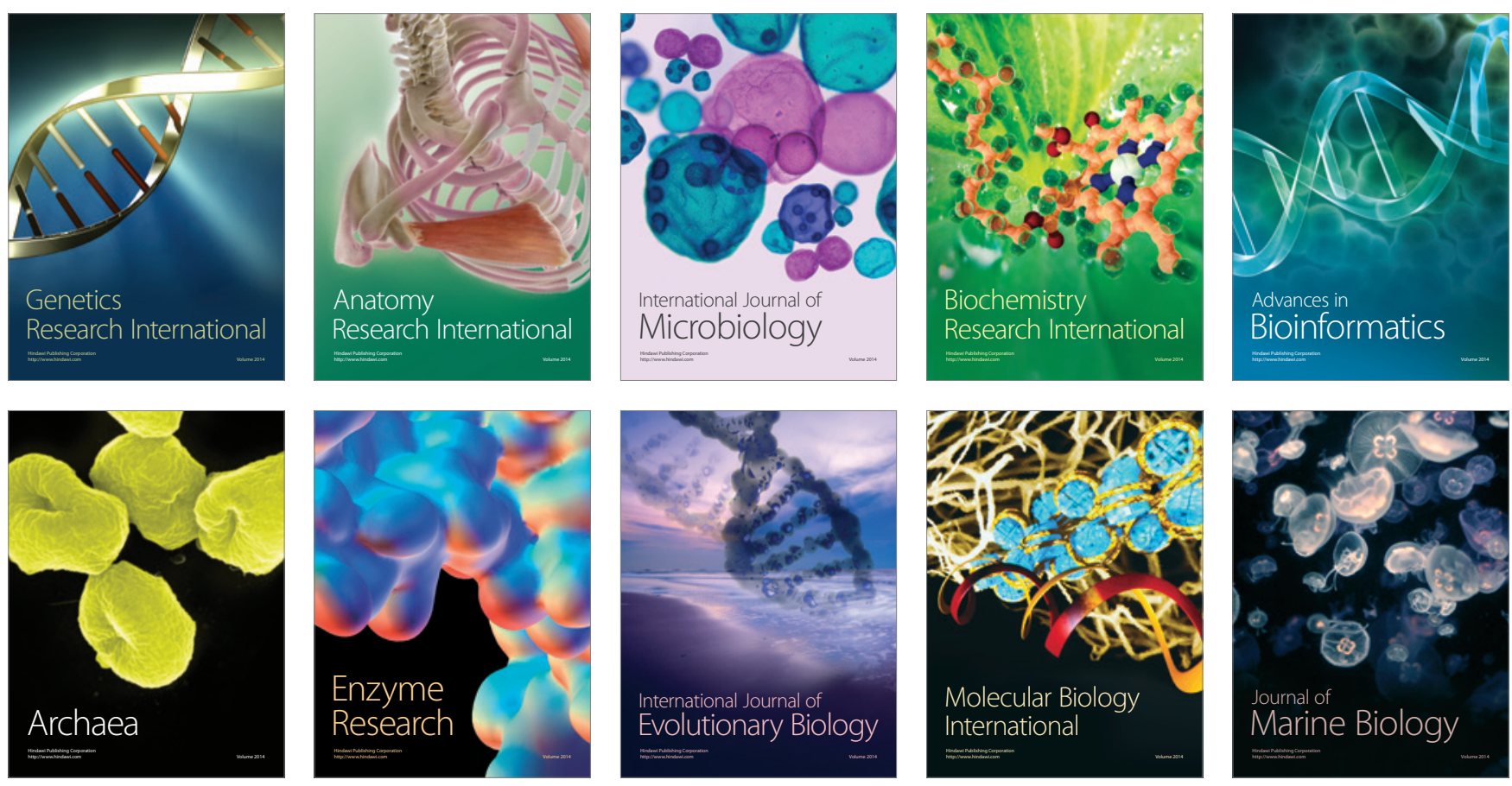